\title{
Researcher dedicated to tumour-suppressing
} genes

Cite as: CMAJ 2017 October 30;189:E1346-7. doi: 10.1503/cmaj.109-5462

Posted on cmajnews.com on Oct. 10, 2017.

D r. William G. Kaelin Jr's research has been dedicated to disentangling the mechanisms by which mutations in tumor-suppressor genes cause cancer. This pursuit has provided a rationale for moving numerous therapies forward to clinical trials in kidney cancer. He has published more than 190 peer-reviewed articles and serves on the editorial boards of multiple journals.

Kaelin is a professor in the Department of Medicine at the Dana-Farber Cancer Institute, Harvard Medical School and a member of the National Academy of Sciences. He received the Canada Gairdner International Award in 2010 for identifying the molecular mechanisms underlying oxygen sensing and regulation in cells. This is an edited version of a recent interview with Kaelin.

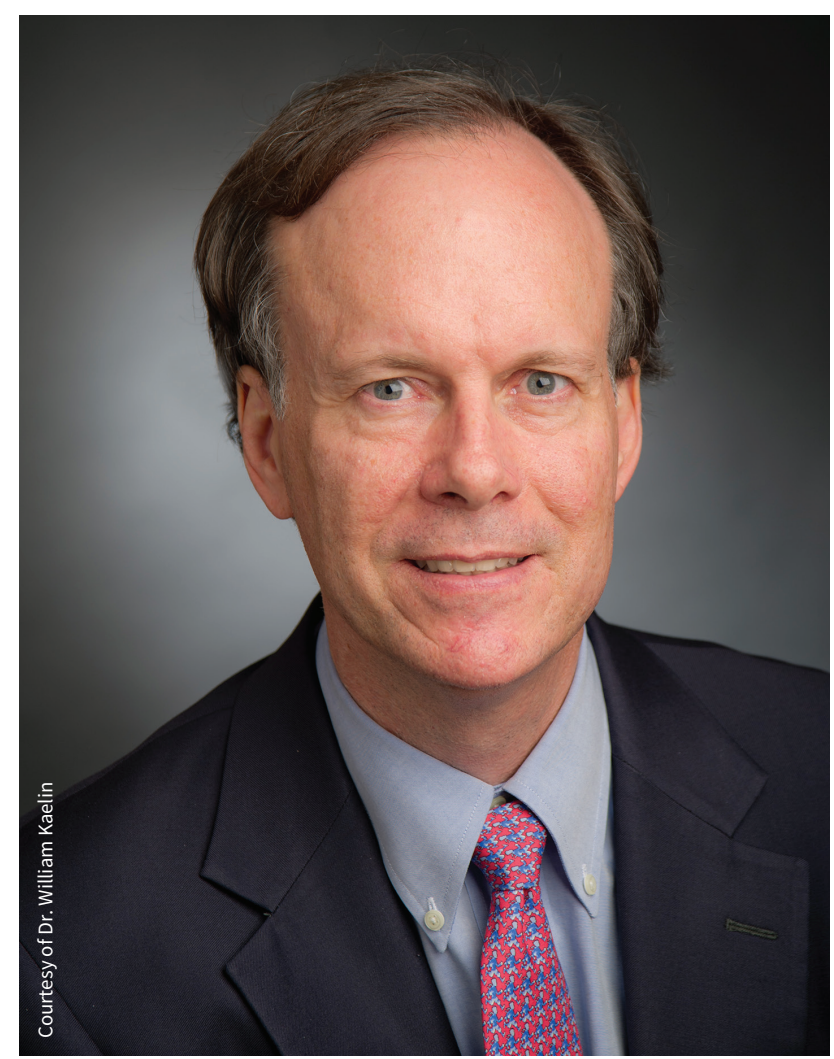

Kaelin thought he'd be a pediatrician, but wound up in research.

\section{What was your path to becoming a physician-scientist?}

"[As] a young boy, I was interested in science and mathematics. I slowly gravitated toward medicine and later did a residency really thinking I was going to be a practicing clinician - I didn't think I was going to be a scientist. I spent time in the laboratory of Dr. David Livingston [thinking] I would return to being a practicing physician, but it turned out David Livingston was a wonderful mentor. For me it was the right lab, the right problem to work on, the right time, and I got the bug and didn't look back."
Why is it so important to publish brick houses and not mansions of straw?

"I understand the pressure that scientists feel today to write papers that feel soup to nuts - that go from a basic discovery to a clinical implication. Unfortunately, the number of claims in papers has steadily increased, but that has come at the cost of corroborating lines of evidence. It's one of the reasons why some papers don't turn out to be as reproducible as we would like. [The] scientists I admire are [those] who, in addition to using the more well-known means of cor- roborating, also come up with clever, less obvious ways of pressure-testing their conclusions. There is this drive to publish papers that are seemingly complete and paint an entire picture, when in fact that's always an illusion because a good paper will almost always raise additional questions."

\section{During your career, did you} ever have a Eureka or an 'ah-ha' moment?

"Fortunately, the answer is yes. Any scientist will tell you they don't happen that frequently, but you remember them when they take place. I've always thought that if we can somehow bottle that feeling and then sprinkle it on young trainees, the world would be a much better place. Unfortunately, scientists do an overly effective job conveying the day-to-day frustrations, but we don't do a good enough job conveying what a privilege it is to do what we do and, on occasion, participate in one of these 'ah-ha' moments."

\section{What sparked your interest in} studying the von Hippel-Lindau tumour suppressor protein?

"When I started working in David Livingston's lab, there were a handful of genes that we knew categorically played a role in cancer. I [thought], everything else being equal, why not work on a gene or process or pathway where there is irrefutable evidence that this plays a role in cancer as opposed to something that turns out to be 
epiphenomenal. My view is let the cancers do the work, so I'm a strong believer in the power of cancer genetics. Fortunately, shortly after I started my lab, a paper appeared describing the von HippelLindau [VHL] gene which is linked to a hereditary cancer syndrome, VHL disease."

How do you see your work on tumor suppressors being translated into patients?

"Once we understood how VHL protein inactivation was contributing to kidney cancer, it suggested some strategies that [may apply to] the clinic. For example, VHL protein inactivation [indirectly causes] upregulation of a factor called vascular endothelial growth factor [VEGF]. That helped to provide a rationale for testing VEGF inhibitors [in] kidney cancer and I think there are now six VEGF inhibitors that have been approved based on positive data in phase III trials. [Similarly I] and my two fellow Gairdner awardees, Gregg Semenza and Peter Ratcliffe, had placed VHL on a pathway where VHL inhibits a transcription factor called hypoxia inducible factor [HIF], which in turn is a master regulator of hundreds of genes, including VEGF. Now our first inhibitor of HIF [is in trials] for kidney cancer.”

What advice do you have for aspiring young scientists and physicianscientists?

"First, [where] you train and who you train with really matters. Mentorship is important, role models are important, being in an environment [surrounded by] people who are smarter than you is important.

Second, [it's] almost too easy to start generating data, including data that might be publishable, [but] there is an opportunity cost to addressing small pedestrian questions when you could be asking big, important, potentially transformative questions. [A] piece of advice would be to say out loud, even if you have to stand in a closet with the door closed, 'what it is you are trying to accomplish?' If it sounds like a very small, incremental question, I would rethink it, [because] it's really important for people to ask bold questions [to] move the field forward."

\section{Christopher S Ahuja, Toronto, Ont.}

Editor's note: To commemorate the recent 30th anniversary of the Canadian Student Health Research Forum (CSHRF), four recipients of Gairdner awards gave public lectures highlighting their achievements. CSHRF participants were selected to interview these laureates. Christopher Ahuja is a neurosurgery resident and PhD candidate in the lab of Dr. Michael Fehlings at the University of Toronto. 